In this series only four of the 11 patients who relapsed had raised concentrations of either or both markers. This compares with an earlier study at this hospital in which $80 \%$ of patients with metastatic disease had raised concentrations of either or both markers (G Read, unpublished observation). With the present scheme of follow up patients with tumours that do not produce markers and in whom the relapse occurs in the abdomen only might be at a disadvantage as the relapse might be diagnosed relatively late, but in this series only one patient fell into this category (case 11) and complete remission was obtained with chemotherapy. Routine estimation of preoperative marker concentrations would be helpful in identifying these patients.

Peckham et al found a predominance of patients with MTU tumours among those who relapsed, ${ }^{9}$ but this was not so in this series. Patients with left sided tumours, however, were significantly more likely to relapse. While further studies are required to confirm this finding, it is intriguing to note a comparison with the improved survival in patients with right sided malignant lymphoma of the testis. ${ }^{11}$ Further studies are also required to provide more information on the pattern of relapse so that the optimum scheme for follow up of patients can be devised. Pathological studies may permit identification of particular patients at risk.

These preliminary results suggest that follow up alone in stage I teratoma of the testis is viable, but at present it is suitable only for large centres with access to specialised investigational techniques, and the optimum scheme for surveillance remains to be determined.

We thank Dr E Gowland, biochemistry department, Withington Hospital, for estimating the serum marker concentrations, Dr M K
Palmer for statistical analysis, and Mrs V Kelly for typing the manuscript.

\section{References}

${ }^{1}$ Peckham MJ. The management of testicular tumours. London: Arnold, 1981:99.

${ }^{2}$ Smithers D. Radiotherapy for patients with tumours of the testicle. $\mathrm{Br} \mathcal{F}$ Urol 1971 ; $43: 83-92$.

${ }^{3}$ Stout R, Hunter RD. Orchidectomy alone for stage I testicular teratoma. Br Med F $1981 ; 283: 885$.

${ }^{4}$ Husband JE, Peckham MJ, McDonald JS, Hendry WF. The role of computed tomography in the management of testicular teratoma. Clin Radiol $1979 \cdot 30 \cdot 243-52$

${ }^{5}$ Nørgaard-Pedersen B, Albrechtsen R, Bagshawe KD, et al. Clinical use of AFP and HCG in testicular tumours of germ-cell origin. Lancet 1978; ii 1042 .

${ }^{6}$ Einhorn LH, Donohue JP. Improved chemotherapy in disseminated testicular cancer. 7 Urol 1977;117:65-9.

${ }^{7}$ Pugh RCB. The pathology of the testis. Oxford: Blackwell Scientific, 1976: 144-6.

${ }^{8}$ Wilkinson PM, Oliver RTD, Williams C, McElwain TJ, Peckham MJ. Etoposide (VP 16-213) as a fourth drug in combination with BVP for treating metastatic germ cell tumours. In: 10th International symposium on the biological characterisation of human tumours. New York, Amsterdam: Martinus Nijhoff (in press)

${ }^{9}$ Peckham MJ, Barrett A, Husband JE, Hendrey WF. Orchidectomy alone in stage I non-seminomatous germ-cell tumours. Lancet 1982;ii:678-80.

${ }^{10}$ Blackledge G, Best JJK, Crowther D, Isherwood I. Computed tomography in the staging of patients with Hodgkin's disease. Clin Radiol 1980;31 143-8.

${ }^{1}$ Read G. Lymphoma of the testis-results of treatment 1960-1977. Clin Radiol $1981 ; 32: 687-92$

\title{
Patients with angina with normal and near normal coronary arteries: clinical and psychosocial state 12 months after angiography
}

\author{
CHRISTOPHER BASS，CLYDE WADE，DAVID HAND，GRAHAM JACKSON
}

\begin{abstract}
The clinical and psychosocial states of 46 patients ( 26 men and 20 women) who had undergone cardiac catheterisation were examined prospectively. All of the patients had insignificant $(<50 \%)$ coronary lesions and had been told that no limitation of activity was necessary. Twelve months after angiography 19 of the patients continued to complain of chest pain. Twenty one reported phobic symptoms, and 13 were found by standardised clinical interview to have psychiatric morbidity. This had been evident at the time of catheterisation in 28 . Twenty three patients had evidence of unexplained breathlessness, 13 were taking psychotropic drugs, 29 were continuing to
\end{abstract}

\section{King's College Hospital, London SE5 9RS}

CHRISTOPHER BASS, MRCPSYCH, lecturer, academic department of psychological medicine

CLYDE WADE, FRACP, research registrar, cardiac department

GRAHAM JACKSON, MRCP, consultant cardiologist, cardiac department

Biometric Department, Institute of Psychiatry, London SE5 8AF DAVID HAND, PHD, senior lecturer

Correspondence to: Dr G Jackson. consult a doctor, and 11 were unable to work because of their symptoms.

Patients initially assessed as having high levels of psychiatric morbidity and raised neuroticism scores were more likely to complain of chest pain one year after angiography. The 19 patients with persistent pain also had significantly higher levels of psychiatric and social morbidity at one year than the 27 patients whose chest pain had lessened during the follow up period.

Those patients who fail to improve after being told that they have normal or nearly normal coronary arteries tend to be a chronically neurotic and socially maladjusted group in whom psychiatric disorder presents with predominantly somatic symptoms.

\section{Introduction}

Among patients referred for cardiac catheterisation because of chest pain up to one third may have either normal coronary arteries or mild non-obstructive atherosclerosis. ${ }^{12}$ The prognosis in these patients is favourable, the incidence of subsequent myocardial infarction and mortality not being increased above that in the population at large when measured 10 years after angiography. ${ }^{3}$ Several recent follow up studies have shown, 
however, that many patients remain disabled and continue to complain of chest pain despite a normal or nearly normal coronary angiogram. ${ }^{4-10}$ The social and economic consequences of this condition are considerable: between $32 \%$ and $51 \%$ of patients remain unable to work after angiography. ${ }^{7} 811$

Using standardised clinical interviews within 24 hours after angiography we found that 28 out of 46 patients with normal or minimally diseased coronary arteries had evidence of psychiatric morbidity. ${ }^{12}$ In addition, 30 of these patients complained of shortness of breath that could not be explained on the basis of organic findings.

We report the results of a prospective study in which physical and psychosocial morbidity as well as functional state in these 46 patients were measured 12 months after angiography. Our aims were to investigate the relation between psychosocial factors and various measures of outcome, with particular regard to psychiatric morbidity, complaints of chest pain, and employment at 12 months.

\section{Patients and methods}

\section{PATIENTS}

From October 1979 to September 1980, 46 patients who underwent cardiac catheterisation for investigation of chest pain were found to have normal or nearly normal coronary arteries and normal left ventricular angiograms. Patients who had clinically recognised forms of heart disease other than coronary disease were excluded. Hypertension and a history of arrhythmia were not considered to be grounds for exclusion. Thirty one patients had normal coronary arteries. Of the remaining 15 patients with minimal disease, 10 had lesions resulting in less than $30 \%$ narrowing of a major vessel, and in five patients the lesions caused an estimated $30-50 \%$ decrease in diameter.

\section{INITIAL INTERVIEW}

The initial interview was conducted within 24 hours after arteriography, before the results had been disclosed. All clinical and laboratory data were obtained by staff not associated with the study. Items in the personal and medical history were recorded in a standardised way. Patients who often experienced breathlessness, symptoms possibly attributable to hypocapnia, and respiratory signs were designated as having an unexplained breathing disorder. This group of patients was established by the method of maximal predictive classification, ${ }^{13}$ which has been described more fully elsewhere. ${ }^{12}$

Mental state was examined by means of a standardised psychiatric interview, ${ }^{14}$ which yields a weighted score whereby psychiatric morbidity is judged to be absent, borderline, moderate, marked, or severe and provides a basis for diagnosis according to the International Classification of Diseases. ${ }^{15}$

Social adjustment and functioning were assessed independently by means of a standardised interview. ${ }^{16}$ This contains sections on all aspects of the patient's social circumstances, and each item is rated on a four point scale ranging from 0 ("satisfactory, no difficulties") to 3 ("severe difficulties or dissatisfaction"). The ratings were grouped under the three principal categories of material conditions, social management and competence, and social satisfaction. Whenever possible the social interview was administered in the presence of someone who knew the patient-for example, spouse, friend, or landlady. Each patient was also asked to complete the Eysenck personality questionnaire. ${ }^{17}$

Each patient with normal coronary arteries was seen after catheterisation and informed by a cardiologist that no coronary disease had been detected and that life expectancy was normal. The remaining 15 patients were told that they had minimal coronary disease and that life expectancy was normal provided they did not smoke. All 46 patients were discharged from the cardiac clinic but advised to consult their family physicians if they continued to have chest discomfort. The referring physicians were also told that the chest pain was unrelated to heart disease and that no limitation of activity was necessary.

\section{FOLLOW UP INTERVIEW}

Twelve months after the initial assessment each patient was visited at home and the psychiatric and social interviews were repeated.
Ratings of breathlessness and other physical symptoms were recorded, and each patient with normal coronary arteries was asked about his or her response to being informed that no coronary disease had been detected. Details of employment and medication prescribed during the follow up period were also noted. Admissions to accident and emergency departments or to hospital for chest pain during the follow up year were designated "morbid events." Additional information was acquired from the patients' general practitioners and from hospital notes.

Finally, chest pain was rated according to the frequency of the symptoms experienced during the previous year as follows: in those patients who had experienced either no pain or a considerable reduction in the frequency of chest pain during the year pain was considered to have improved, whereas in those who reported either no overall change or an increase in the frequency of chest pain over the year pain was classified as chronic.

\section{Results}

No cardiological cause of the chest pain was found in any of the 31 patients with normal coronary arteries, and the coronary lesions in the 15 patients with minimal disease were not considered to be responsible for their symptoms. Only one patient, with minimal disease, who had a hiatus hernia, was relieved of chest pain after appropriate treatment.

\section{CLINICAL FEATURES}

No patient died or had a myocardial infarction during the period of follow up. Only three of the 46 patients had been entirely free of chest pain during the year. Of the remainder, 24 reported a considerable reduction in the frequency of chest pain, 15 reported no overall change in the frequency of the symptom, and in four chest pain had become more frequent.

Twenty three of the 46 patients were assigned a diagnosis of unexplained breathing disorder at follow up. There was a relation between this diagnosis and continued complaints of chest pain: 16 $\left(84^{\circ}{ }_{\circ}^{\prime}\right)$ of the 19 patients whose chest pain had failed to improve were diagnosed as having an unexplained breathing disorder compared with seven $(26 \%)$ of the 27 patients who reported a reduction in the frequency of chest pain $\left(\gamma^{2}=12.9 ; \mathrm{p}<0.001\right)$.

Use of medical facilities-Eleven of the 46 patients (seven with normal coronary arteries and four with minimal disease) had developed clear cut "morbid events"during the intervening 12 months. One patient with minimal disease had been readmitted to hospital because of persistent chest pain, and the remaining 10 patients had visited accident and emergency departments because of chest pain (seven with normal arteries and three with minimal disease). Twenty seven patients were still consulting their general practitioners because of chest pain one year after catheterisation. Sixteen of these patients were regularly attending cardiology clinics, and two patients with normal coronary arteries were consulting gastroenterologists. No follow up had been arranged for 17 of the patients. Six $(19 \%)$ of the 31 patients with normal coronary arteries continued to express the belief that they had heart disease despite reassurance from a cardiologist that no coronary disease had been detected and that the prognosis was favourable.

Employment state-At the time of angiography 20 patients were unable to work because of recurrent pain. Nine of these 20 patients $\left(45^{\circ}{ }_{0}\right)$ had returned to work by the follow up assessment. The 11 other patients remained so incapacitated by their symptoms that they were unable to resume employment, and five of these were receiving invalidity benefits (two patients with normal coronary arteries and three with minimal disease).

Medication-Fifteen of the 31 patients with normal coronary arteries were taking beta blockers, calcium antagonists, or nitrates (alone or in combination) for their symptoms one year after catheterisa-

TABLE I-Relation of social maladjustment scores to psychiatric case state at 12 month follow up in 28 patients initially classified as psychiatric cases. Figures are means $(S E)$

\begin{tabular}{lccc}
\hline Psychiatric state at follow up & $\begin{array}{c}\text { Material } \\
\text { conditions }\end{array}$ & $\begin{array}{c}\text { Social } \\
\text { management }\end{array}$ & $\begin{array}{c}\text { Social } \\
\text { satisfaction }\end{array}$ \\
\hline Non-cases $(\mathrm{n}=16)$ & $2.38(0.39)$ & $2.56(0.41)$ & $2 \cdot 44(0.56)$ \\
Cases $(\mathrm{n}=12)$ & $3.75(0 \cdot 46)$ & $\mathbf{4} \cdot 17(0.69)$ & $6.08(1.45)$
\end{tabular}


tion. Another patient with atrial fibrillation was receiving digoxin. Nine patients $(29 \%)$ were taking psychotropic drugs prescribed by their general practitioners. Seven of the 15 patients with minimal disease $(47 \%)$ were taking beta blockers at follow up, four were receiving psychotropic drugs from their general practitioners, and four were taking antihypertensive drugs. A further four $(27 \%)$ were not receiving any drugs.

\section{INITIAL PSYCHOSOCIAL FACTORS RELATED TO PSYCHIATRIC OUTCOME}

For the 28 patients designated psychiatric cases at the initial assessment the risk of being a case 12 months later was $43 \%$ (12 cases among 28 patients seen at follow up), whereas for the 18 initial non-cases it was only $6 \%$ (one case among 18 patients).

Of the 28 initial cases, 12 were still cases at 12 months and 16 had become non-cases at 12 months. The mean (SE) initial psychiatric morbidity score in those who remained cases $(22.50(1.60))$ was significantly higher than that in those who became non-cases $(16.75$ $(0.85))(t=3.40 ;$ df $26 ; \mathrm{p}<0.01)$. In other words, the risk of remaining a case at follow up was greater the more severe the psychiatric disorder at the initial assessment.

There were no differences between those who remained cases and those who became non-cases with respect to any demographic or psychological data collected at the initial interview. At the follow up assessment, however, the social circumstances in the two patient groups were appreciably different. Table I shows that the 12 patients who remained cases throughout the year had considerably higher ratings of social dissatisfaction at one year (mean $6.08(1.45)$ ) than the 16 patients who ceased to be cases $(2.44(0.56))(\mathrm{p}<0.05$; MannWhitney U test).

Anxiety neurosis remained the most common psychiatric diagnosis at follow up, being diagnosed in 11 of the 13 psychiatric cases. Twenty four patients had reported phobic symptoms at the initial assessment, and in all but three these symptoms persisted throughout the follow up period. Five patients remained sufficiently restricted to have to avoid certain situations-for example, crowded rooms, shops, public transport.

RELATION BETWEEN CHEST PAIN AT FOLLOW UP AND INITIAL PSYCHOSOCIAL VARIABLES

Fourteen of the 27 patients whose pain was considered to have improved and 14 of the 19 patients whose pain was classified as chronic had been designated psychiatric cases at the initial assessment. Both at the initial assessment and at one year patients classified as having chronic pain had significantly higher mean psychiatric scores than those whose pain was considered to have improved at the follow up assessment (table II). Examination of the social scores showed that

TABLE II-Changes in psychiatric and social scores over follow up year in patients in whom chest pain improved and in those with chronic pain

\begin{tabular}{lccc}
\hline & $\begin{array}{c}\text { Pain improved } \\
(\mathrm{n}=27)\end{array}$ & $\begin{array}{c}\text { Chronic pain } \\
(\mathrm{n}=19)\end{array}$ & Significance (p) \\
\hline Psychiatric mean score: & & & \\
$\quad$ Initially & 12.18 & 17.84 & $<0.02$ \\
At follow up & 7.59 & 15.05 & $<0.001$ \\
Mean (SEM) change & $-4.59(0.93)$ & $-2.79(1.11)$ & $\mathrm{NS}$ \\
Social adjustment mean score: & & & \\
Initially & 7.81 & 9.58 & $\mathrm{NS}$ \\
At follow up & 5.07 & 11.95 & $<0.001$ \\
Mean (SEM) change & $-2.74(0.61)$ & $+2.37(0.56)$ & 0.001 \\
\hline
\end{tabular}

patients with chronic pain tended to have higher mean social adjustment scores (reflecting worse adaptation) at follow up than at the initial assessment, although this tendency was not significant. This deterioration in social adjustment occurred despite a reduction in the mean psychiatric scores in this group (table II).

The data in table III show that patients with chronic pain had significantly higher psychiatric morbidity and neuroticism scores at the initial assessment. They had also experienced chest pain for a significantly longer time before catheterisation than patients whose pain improved. Although there was a tendency for these patients to be younger and have higher initial social scores, these were not significant.
TABLE III-Comparison of initial psychosocial and personality scores in patients with improved and chronic chest pain at follow up

\begin{tabular}{|c|c|c|c|c|c|c|}
\hline & \multicolumn{2}{|c|}{$\begin{array}{l}\text { Improved pain } \\
(\mathrm{n}=27)\end{array}$} & \multicolumn{2}{|c|}{$\begin{array}{l}\text { Chronic pain } \\
(\mathrm{n}=19)\end{array}$} & \multirow{2}{*}{$t$} & \multirow{2}{*}{$\mathrm{p}$} \\
\hline & Mean & SEM & Mean & SEM & & \\
\hline Age (years) & $47 \cdot 7$ & $1 \cdot 61$ & $44 \cdot 3$ & $2 \cdot 03$ & $1 \cdot 30$ & NS \\
\hline $\begin{array}{l}\text { Duration of symptoms } \\
\text { (months) } \\
\text { Psychiatric morbidity }\end{array}$ & $37 \cdot 1$ & $5 \cdot 50$ & $67 \cdot 8$ & $13 \cdot 78$ & $2 \cdot 07$ & $<0.05$ \\
\hline score & $12 \cdot 18$ & $1 \cdot 25$ & $17 \cdot 84$ & $1 \cdot 74$ & $2 \cdot 71$ & $<0.02$ \\
\hline $\begin{array}{l}\text { Social interview schedu } \\
\text { Overall social score } \\
\text { Material conditions } \\
\text { Social management } \\
\text { Social satisfaction }\end{array}$ & $\begin{array}{l}7 \cdot 81 \\
2 \cdot 44 \\
2 \cdot 26 \\
3 \cdot 11\end{array}$ & $\begin{array}{l}1 \cdot 00 \\
0 \cdot 34 \\
0.37 \\
0.53\end{array}$ & $\begin{array}{l}9 \cdot 58 \\
2 \cdot 63 \\
3 \cdot 11 \\
3 \cdot 84\end{array}$ & $\begin{array}{l}1.40 \\
0.47 \\
0.51 \\
0.80\end{array}$ & & $\begin{array}{l}\text { NS* } \\
\text { NS* } \\
\text { NS* } \\
\text { NS* }\end{array}$ \\
\hline $\begin{array}{l}\text { Eysenck personality que } \\
\text { Neuroticism } \\
\text { Extraversion } \\
\text { Psychoticism } \\
\text { Lie score }\end{array}$ & $\begin{array}{c}\text { ionnaire } \\
10 \cdot 26 \\
12 \cdot 74 \\
2 \cdot 78 \\
9.89\end{array}$ & $\begin{array}{l}0.82 \\
0.92 \\
0.40 \\
0.95\end{array}$ & $\begin{array}{r}13.11 \\
11.95 \\
3.26 \\
10.21\end{array}$ & $\begin{array}{l}0.89 \\
1.21 \\
0.58 \\
1.33\end{array}$ & $\begin{array}{l}2.33 \\
0.53 \\
0.72 \\
0.20\end{array}$ & $\begin{array}{l}<0.05 \\
\text { NS } \\
\text { NS } \\
\text { NS }\end{array}$ \\
\hline
\end{tabular}

* Mann-Whitney U test.

\section{Discussion}

Nineteen of the 46 patients continued to complain of chest pain one year after angiography. The symptom persisted despite reassurance from a cardiologist that no appreciable disease was present and that the prognosis was favourable. This finding is consistent with two recent follow up studies of patients with normal or nearly normal coronary arteries: these found that after mean follow up periods of three and a half years ${ }^{9}$ and 10 years $^{3} 38 \%$ and $40 \%$ of patients respectively continued to complain of chest pain.

Those patients whose chest pain either increased in frequency or failed to improve during the year had significantly higher psychiatric morbidity and neuroticism scores at the initial assessment than those patients whose chest pain lessened. Like Pasternak et $a l^{9}$ we found that continuing chest pain was significantly more common in patients with a longer duration of pain before angiography. The persistence of psychiatric morbidity in the patients with chronic pain was reflected by their continuing use of psychotropic drugs: eight of these patients $(42 \%)$ were taking either an anxiolytic or an antidepressant drug at follow up. In addition, these patients had higher social maladjustment scores at follow up than at the initial assessment. These higher scores of psychiatric and social morbidity in patients with continuing chest pain, together with the long histories of similar complaints, raised neuroticism scores (a measure of "trait" anxiety), and continued use of psychotropic drugs suggest that these patients are a chronically neurotic and socially maladjusted group in whom psychiatric disorder presents with predominantly somatic symptoms.

Although only six of the 31 patients with normal coronary arteries believed that they had heart disease at follow up, 15 continued to receive prescriptions for cardiac medication from their general practitioners and 19 were consulting doctors one year later. The continuing administration of cardiac drugs suggests that doctors are uncertain about the nature and cause of the illness. Psychiatric morbidity, however, is a known determinant of consulting behaviour: Mechanic ${ }^{18}$ suggested that patients with psychiatric disorder consult their doctors more frequently than those without. The discrepancy between the patients' lack of conviction about having heart disease and their continuing use of medical facilities may be attributable not only to the physicians' uncertainty about the diagnosis but also to continuing psychiatric morbidity in the patients.

Eleven of the 46 patients remained sufficiently disabled at follow up for them to be unable to work. These findings are consistent with those of two previous American studies, ${ }^{7} 8$ both of which reported even higher proportions unemployed at follow up than the present investigation. Lavey and Winkle? suggested that an element of "secondary gain" was responsible for the continuing high proportions of patients unemployed $(44 \%$ in their study) and claiming disability benefits. The 
reasons for these high rates of disability and unemployment in American studies is not clear, although Pasternak et al commented that "it is often hard to ascertain whether disability is directly due to the pain itself or to emotional factors leading to secondary gain from the pain." 9 We found that unemployment at follow up was associated with high levels of psychiatric and social morbidity: of the 11 patients who remained unable to work, seven were designated psychiatric cases and 10 had had previous episodes of psychiatric illness.

Previous studies have not emphasised that many patients with normal or nearly normal coronary arteries have a polysymptomatic disorder. Sixty five per cent of our patients complained of fatigue at 12 months and half reported symptoms of breathlessness that could not be explained on the basis of organic lung disease. The relation between psychiatric morbidity and breathlessness is poorly understood. Breathlessness may occur not only as a somatic manifestation of an anxiety state ${ }^{19}$ but also as a habitual characteristic in a patient with no evidence of organic lung disease. ${ }^{20}$ In our study there was an association between phobic symptoms, complaints of breathlessness, and chest pain, and four fifths of the patients with phobic symptoms reported having breathing difficulties in anxiety provoking situations. This relation between phobic symptoms and breathlessness has been recorded previously, ${ }^{21}{ }^{22}$ and Wittkower et al suggested that breathlessness is often the physiological correlate of the psychological symptom of claustrophobia. ${ }^{23}$

Closer scrutiny of the symptom profiles showed that over half the patients in the present study with normal or nearly normal coronary arteries showed many features common to clinical syndromes that have been variously described in the past as Da Costa's syndrome, ${ }^{24}$ the effort syndrome, ${ }^{25}$ and neurocirculatory asthenia. ${ }^{26}$ Table IV shows the incidence of the main symptoms

TABLE IV-Comparison of symptoms reported by patients with the effort syndrome, neurocirculatory asthenia, and chest pain with normal and nearly normal coronary arteries (figures are numbers $(\%)$ of patients)

\begin{tabular}{lccc}
\hline Symptom & $\begin{array}{c}\text { Effort syndrome24 } \\
(\mathrm{n}=200)\end{array}$ & $\begin{array}{c}\text { Neurocirculatory } \\
\text { asthenia } \\
(\mathrm{n}=60)\end{array}$ & $\begin{array}{c}\text { Present study } \\
(\mathrm{n}=46)\end{array}$ \\
\hline Chest pain & $156(78)$ & $51(85)$ & $46(100)$ \\
Breathlessness & $186(93)$ & $54(90)$ & $30(65)$ \\
Palpitations & $178(89)$ & $58(97)$ & $25(54)$ \\
Fatigue & $176(88)$ & $57(95)$ & $30(65)^{*}$ \\
Sweats & $160(80)$ & $27(45)$ & $26(57)$ \\
Faintness, giddiness & $158(79)$ & $47(78)$ & $27(59)$ \\
Paraesthesiae & $112(56)$ & $35(58)$ & $26(57)$ \\
Syncope & $70(35)$ & $22(37)$ & $12(26)$ \\
Sighs & $124(62)$ & $47(79)$ & $23(50)$ \\
Smothering & $158(79)$ & $24(40)$ & $15(33)$ \\
Nervousness & $153(88)$ & $28(61) \dagger$ \\
& & 53 &
\end{tabular}

* Feelings of fatigue that either caused considerable distress or caused the patient to modify his normal activities.

$+61 \%$ of patients in the present study were designated psychiatric "cases" using the standardised psychiatric interview.

as recorded by previous authors and as found in the present series of 46 cases. The symptoms in these patients are unlikely to have been the consequence of underlying cardiac disease. Rather, we suggest that they were somatic manifestations of psychiatric morbidity and overbreathing, which often coexist with a phobic diathesis.

The results suggest that those patients with minimal coronary lesions who are least likely to improve after arteriography have demonstrable psychiatric and social morbidity. In many of these patients the chest pain, which is similar to angina, is part of a polysymptomatic disorder. Patients with normal or nearly normal coronary arteries who continue to complain of chest pain after angiography would benefit from psychiatric assessment before further invasive investigations are undertaken.
We thank members of the cardiac department for their help, Professor R H Cawley for his help and criticism, Dr P Gishen for examining the coronary angiograms, and Brigitte Barnett for help in preparing the manuscript.

\section{References}

1 Proudfit WL, Shirley EK, Sones PM. Selective cinecoronary arteriography. Correlation with clinical findings in 1000 patients. Circulation 1966;33: 901-10.

2 Marchandise B, Bourassa MG, Chaitman BR, Lesperance J. Angiographic evaluation of the natural history of normal coronary arteries and mild coronary atherosclerosis. Am 7 Cardiol 1978;41:216-20.

3 Proudfit WL, Bruschke AVG, Sones PM. Clinical course of patients with normal or slightly or moderately abnormal coronary arteriograms: 10 year follow-up of 521 patients. Circulation 1980;62:712-7.

4 Waxler EB, Kimbiris D, Dreifus LS. The fate of women with normal coronary arteriograms and chest pain resembling angina pectoris. $A m \mathfrak{F}$ Cardiol $1971 ; 28: 25-32$

${ }^{5}$ Kemp HG, Vokonas PS, Cohn PF, Gorlin R. The anginal syndrome associated with normal coronary arteriograms. Am $\mathcal{F}$ Med 1973;54:735-42.

${ }^{6}$ Bemiller CR, Pepine CJ, Rogers AK. Long term observations in patients with angina and normal coronary arteriograms. Circulation 1973;47: 36-43.

${ }^{7}$ Lavey EB, Winkle RA. Continuing disability of patients with chest pain and normal coronary arteriograms. F Chronic Dis 1979;32:191-6.

${ }^{8}$ Ockene IS, Shay MJ, Alpert JS, Weiner BH, Dalen JE. Unexplained chest pain in patients with normal coronary arteries. A follow-up study of functional status. $N$ Engl F Med 1980;303:1249-52.

${ }^{9}$ Pasternak RC, Thibault GE, Savoia $M$, De Sanctis RW, Hutter AM. Chest pain with angiographically insignificant coronary arterial obstruction. Clinical presentation and long-term follow-up. $\mathrm{Am} \mathcal{F} \mathrm{Med}$ $1980 ; 68: 813-7$.

${ }^{10}$ Isner JM, Salem DN, Banas JS, Levine HJ. Long-term clinical course of patients with normal coronary arteriography: follow-up study of 121 paticnts with normal or nearly-normal coronary arteriograms. Am Heart f $1981 ; \mathbf{1 0 2}: 645-53$.

11 Faxon DP, McCabe CH, Kreigel DE, Ryan TJ. Therapeutic and economic value of a normal coronary arteriogram. Am f Med 1982;73:500-5.

12 Bass C, Cawley RH, Wade C, et al. Unexplained breathlessness and psychiatric morbidity in patients with normal and abnormal coronary arteries. Lancet 1983 ; : :605-9.

13 Gower JC. Maximal predictive classification. Biometrics $1974 ; 30: 643-53$.

14 Goldberg DP, Cooper B, Eastwood MR, Kedward HB, Shepherd M. A standardised psychiatric interview for use in community surveys. British fournal of Preventive and Social Medicine 1970;24:18-23.

15 World Health Organisation. Mental disorders: glossary and guide to their classification. International Classification of Diseases. 9th revision. Geneva: World Health Organisation, 1978.

${ }^{16}$ Clare AW, Cairns VE. Design, development and use of a standardised interview to assess social maladjustment and dysfunction in community studies. Psychol Med 1978;8:589-604.

17 Eysenck HJ, Eysenck SBG. Manual of the Eysenck personality questionnaire. London: Hodder and Stoughton, 1975.

${ }^{18}$ Mechanic D. Effect of psychological distress on perceptions of physical health and use of medical and psychiatric facilities. $\mathcal{f}$ Human Stress $1978 ; 4: 26-32$.

19 Marks I, Lader M. Anxiety states (anxiety neurosis): a review. $\mathcal{f}$ Nerv Ment Dis 1973;156:3-18.

${ }^{20}$ Lum LC. The syndrome of habitual chronic hyperventilation. In: Hill $\mathrm{OW}$, ed. Recent advances in psychosomatic medicine. Vol III. London: Butterworths, 1976.

21 Tucker WI. Diagnosis and treatment of the phobic reaction. Am $\mathcal{F}$ Psychiatry 1956;112:825-30.

22. Garssen B, van Veenendaal W, Bloemink R. Agoraphobia and the hyperventilation syndrome. Behav Res Ther (in press).

23 Wittkower E, Rodger TF, Macbeth Wilson AT. Effort syndrome. Lancet $1941 ; \mathrm{i}: 531-5$.

24 Wood P. Da Costa's syndrome (or effort syndrome). Br Med $\mathcal{F} 1941$; : 767-72, 805-11, 845-51.

${ }^{25}$ Lewis T. The soldier's heart and the effort syndrome. London: Shaw and Sons, 1918.

${ }_{26}$ Oppenheimer BS, Levine SA, Morison RA, Rothschild MA, St Lawrence W, Wilson FN. Report on neurocirculatory asthenia and its management. Military Surgeon 1918;42:409-26, 711-9.

27 Wheeler EO, White PD, Reed EW, Cohen ME. Neurocirculatory asthenia (anxiety neurosis, effort syndrome, neurasthenia). A 20 year follow-up study of 173 patients. $\mathcal{F} A M A 1950 ; 142: 878-89$.

(Accepted 4 August 1983) 